\title{
STROKE NETWORK STRATEGY IN ISTANBUL: A THREE-MONTH PERIOD RESULTS
}

\author{
Koyuncu B ${ }^{1}$, Onalan A ${ }^{1}$, Akil E², Bajrami A ${ }^{3}$, Pourmohammed R ${ }^{3}$, Senol PN ${ }^{1}$, Geyik S ${ }^{1}$, Tolun R ${ }^{1}$, Krespi $\mathrm{Y}^{1}$ \\ ${ }^{1}$ Isstinye University Liv Hospital, Department of Neurology, Istanbul ${ }^{2}$ Dicle University Faculty of Medicine, Department of Neurology, Diyarbakir \\ ${ }_{3}^{3}$ Aydin University, Florya Medicalpark Hospital, İstanbul
}

BACKGROUND: In Istanbul, a city with high population and chaotic traffic, acute stroke patients (ASP) are transferred to the nearest hospital but pre-hospital emergency system is not well organized. We established a Stroke (Brain Angiography and Stroke Centre-BASC) Network including 3 comprehensive stroke centre (CSC) that are strategically located in Istanbul in order to ensure easy-access to the stroke patients.

METHODS: In BASC Network, the CSCs are a SITS member and Angel Hospital. The patients are treated according to standardized institutional guidelines and evaluated with $\mathrm{CT}$ and/or MRI including RAPID software since December 2017. We analysed the preliminary quality performance data of ASP between October - December 2017.

RESULTS: During this period, 186 patients were admitted, the mean age was 68 and 57\% was male. Demographics and vasculary risc factor are presented in table 1. Median onset-to-door (ODT) time of 186 admitted patients (\%51 referral) was 255 minutes. Revascularization therapy (27\% only IVrTPA, 27\% bridging, $46 \%$ only endovascular) was performed in 74 patients $(\mathbf{3 9 . 8 \%})$. Within the eligible patients that are admitted within $0-4.5 \mathrm{~h}$ period $(47.3 \%) \mathbf{9 8 \%}$ received IVrTPA. In the $0-6 \mathrm{~h}$ period $(56.5 \%)$ all the eligible patients $(44 / 105),>6 \mathrm{~h}$ period 10 patients (10/81) received thrombectomy. MCA M1 occlution rate was $22.3 \%$, ICA (internal carotis artery) proximal pathology $15.5 \%$ and M2M3 occlution 21.4\%. The rate of good prognosis (mRS 0-2) at discharge and in-hospital mortality was $49,2 \%$ and $3,8 \%$ respectively.

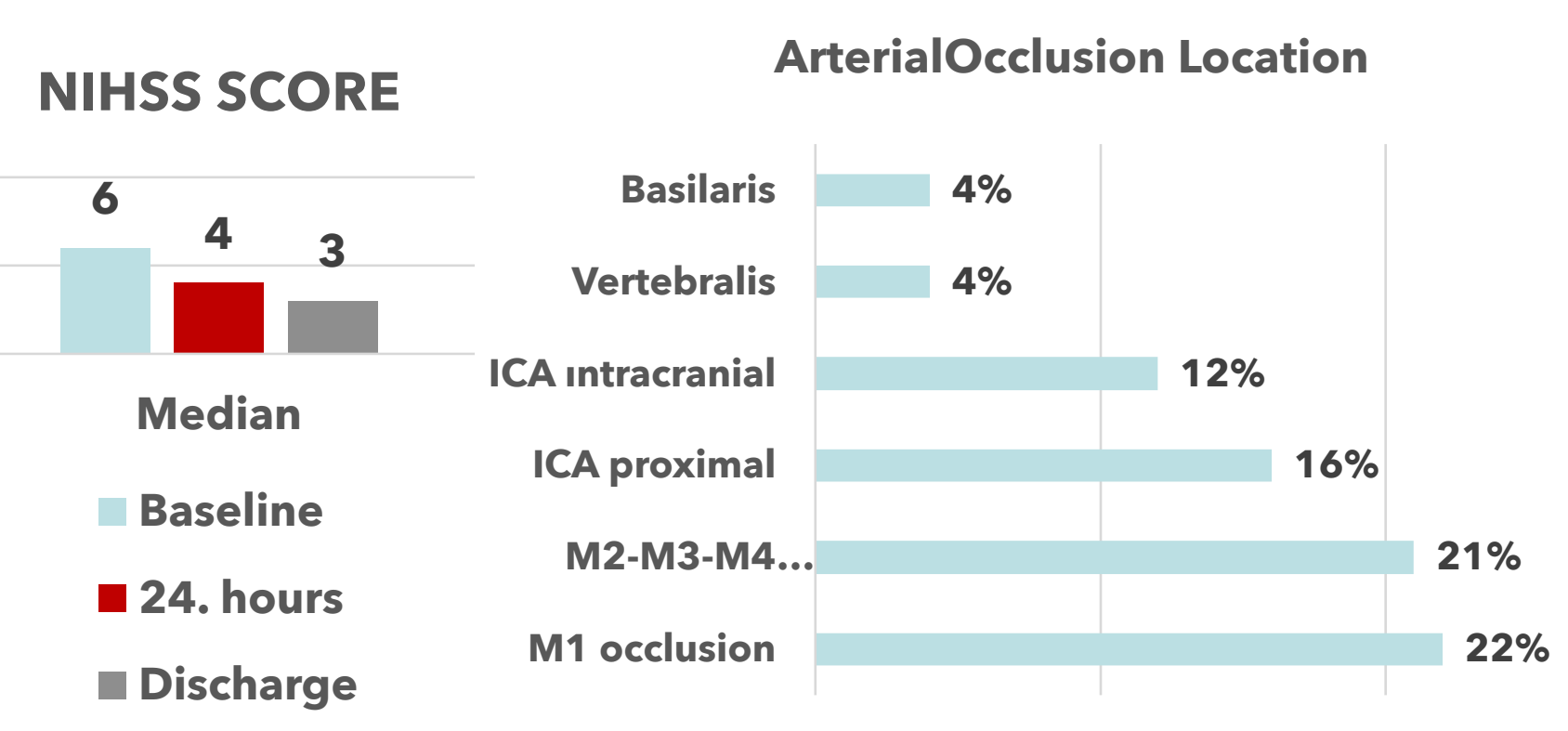

DISCUSSION: In this newly established stroke network the patients are admitted to the nearest CSC. In this newly established system treatment is intensive and effective, rate of the recanalizaton and DIT are similar to literature. Reaching to the shortest time in DNT is our primarily target $(1,2,3)$.

\begin{tabular}{|l|c|}
\hline \multicolumn{1}{|c|}{ Table 1: DEMOGRAPHICS } & $\%$ \\
\hline Age $>\mathbf{8 0}$ & $\mathbf{1 8 \%}$ \\
\hline Age mean & $\mathbf{6 8}$ \\
\hline Male & $\mathbf{5 7 \%}$ \\
\hline Atrial Fibrillation & $\mathbf{3 6 \%}$ \\
\hline TACS & $\mathbf{3 3 \%}$ \\
\hline LACS & $\mathbf{2 0 \%}$ \\
\hline Hypertension & $\mathbf{7 5 \%}$ \\
\hline Hyperelipidemia & $\mathbf{4 4 \%}$ \\
\hline Diabetes Mellitus & $\mathbf{3 8 \%}$ \\
\hline Smoking & $\mathbf{2 2 \%}$ \\
\hline Coronary Artery Disease & $\mathbf{3 1 \%}$ \\
\hline Previous Stroke $>$ 3 months & $\mathbf{1 5 \%}$ \\
\hline
\end{tabular}

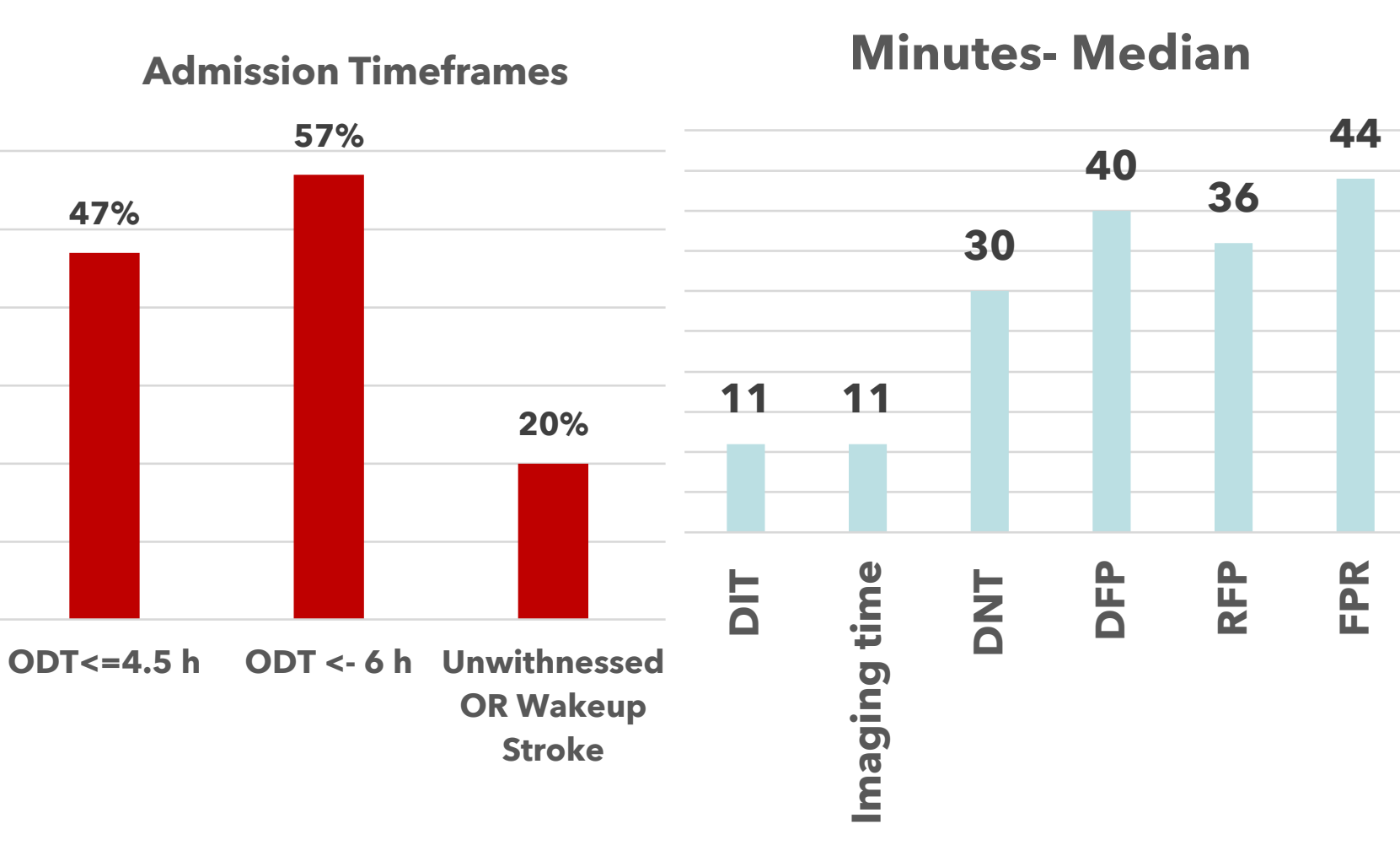

Table 2 QUALITY DATA RESULTS

SITS-MOST

Decompressive Surgery

Dysphagia Screening

$5,4 \%$

$94,1 \%$

Antithrombotic treatment

DVT prophylaxis

Pulmonary infection

$99,5 \%$

$99,5 \%$

$12,9 \%$

$1,1 \%$

Urinary tract infection

$0,5 \%$

The compression ulcer

$12,9 \%$

Diagnostic neuroangiography

$8,6 \%$

Intracranial anjioplasty or stenting $\quad 1,1 \%$

Lipid-lowering therapy

$97 \%$

Antithrombotic therapy on discharge $\quad 95,7 \%$

Atrial fibrillation

$38,7 \%$

Anticoagulant therapy

$82 \%$ 3th Month Prognosis $44 \%$

$16 \%$

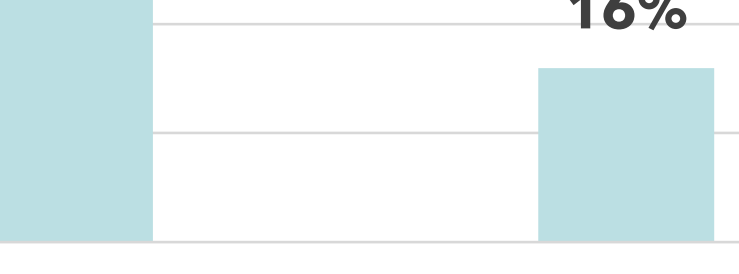

MRS 0-2

Mortality 